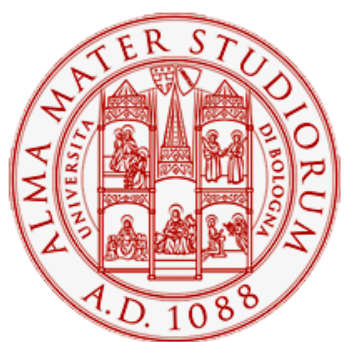

Alma Mater Studiorum - Università di Bologna DEPARTMENT OF ECONOMICS

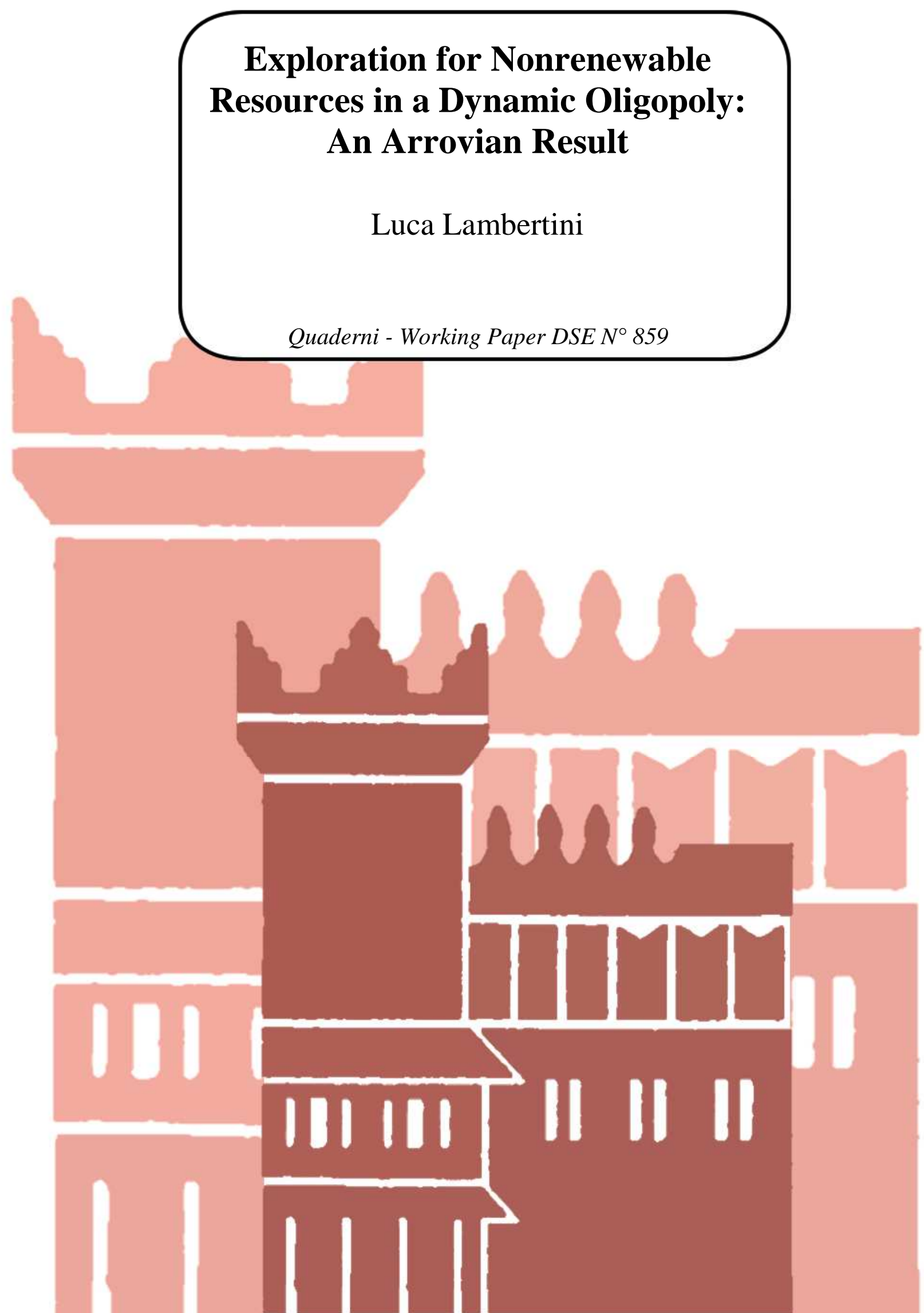




\title{
Exploration for Nonrenewable Resources in a Dynamic Oligopoly: An Arrovian Result
}

\author{
Luca Lambertini \\ Department of Economics, University of Bologna \\ Strada Maggiore 45, 40125 Bologna, Italy \\ luca.lambertini@unibo.it
}

January 6, 2013

\begin{abstract}
I investigate two versions of a differential Cournot oligopoly game with nonrenewable resource exploitation, in which each firm may either exploit its own private pool or exploit a common pool jointly with the rivals. Firms use a deterministic technology to invest in exploration activities. In both models, there emerges that (i) the individual exploration effort is higher when each firms has exclusive rights on a pool of its own, and (ii) depending on the assumptions on technology and demand, the aggregate exploration effort is either constant or increasing in the number of firms.
\end{abstract}

JEL Codes: C73, L13, Q30

Keywords: differential games, natural resources, oligopoly 


\section{Introduction}

The point of departure of the literature on natural resource economics is that unregulated profit-seeking firms will not, in general, spontaneously internalise the consequences of their behaviour on the environment, much the same as we know about polluting emissions. This raises the issue of extinction/exhaustion.

Indeed, a large part of the debate on nonrenewables includes exploration into the picture, with and without uncertainty affecting the exploration process (see Peterson, 1978; Deshmuk and Pliska, 1980; Arrow and Chang, 1982; Mohr, 1988; and Quyen, 1988, 1991). In the early literature, exploration is motivated by two reasons. The first is the incentive to obtain information about the uncertain size or features (e.g., quality) of the resource stock; the second is the incentive to abate extraction costs through exploration, in situations where the level of such costs is inversely related with the size of proven reserves. In Mohr (1988), where uncertainty is assumed away and the extraction cost is nil, the investments in expensive exploration activities are driven by an incentive to preempt rivals by appropriating some portion of a still unexplored common pool resource, thereby ensuring exclusive property rights on this portion and preventing its use by other firms. ${ }^{1}$

A recent contribution (Boyce and Vojtassak, 2008), adds costly exploration under uncertainty into the framework known as the theory of 'oil'igopoly dating back to Salant (1976), and further developed by Loury (1986) and Polasky $(1992,1996)$. This approach investigates the relationship between known reserves, production and exploration incentives. It predicts that firms holding larger proved reserves will tend to produce outputs which are larger in absolute size but smaller as a proportion of their reserves as compared to rivals with smaller proved reserves. Adding exploration activities to the model, Boyce and Vojtassak (2008) conclude that firms whose proved reserves gets exhausted before their owners are able to convert their unproved reserves into proved ones have a strict incentive to overinvest in exploration activities, a feature which should be easily observed, and this empirical prediction is consistent with available data concerning the last decades.

Another approach deals with the search for the so-called backstop technologies, i.e., substitute technologies using renewable (and possibly, but not necessarily, green) resources replacing the traditional ones. The incentives

\footnotetext{
${ }^{1}$ For an overview of the literature, see Lambertini (2013).
} 
of firms or countries to devote R\&D efforts in search substitutes of an exhaustible resources have also been investigated by a number of authors (Davidson, 1978; Hoel, 1978; Dasgupta, Gilbert and Stiglitz, 1983; Olsen, 1988; Harris and Vickers, 1995). Under perfect certainty (i.e., if the nature of the innovation is known a priori) and the date of its discovery is deterministic), importers may strategically affect the extraction path of the exporters by manipulating the timing of innovation. ${ }^{2}$

My aim here is to set up two different models describing differential games taking place in a Cournot industry, in which firms exploit a nonrenewable resource and may invest in costly exploration activities to enlarge the stock of resource. This is modelled under two alternative assumptions, either allowing each firm exclusive rights on the exploitation of a private pool, or compelling all firms to extract the resource from a common pool. In both versions of the model, and under both assumptions, there emerge a multiplicity of steady state equilibria, among which one is the 'myopic' outcome leading to depletion, while another shows the existence of spontaneous incentives to invest in exploration activities even in absence of a dedicated regulatory policy. In this respect, the present analysis offer results largely differing from those typically emerging in dynamic market models dealing with polluting emissions (see, e.g., Benchekroun and Long, 1998, 2002).

Comparing the firms' efforts in the two alternative scenarios where either private pools are exploited or a single pool exists, there emerges - not surprisingly - that the public nature of the common pool curtails firms' incentives to invest in exploration as compared to the situation in which the benefits of private access can be fully appropriated by each firm, a classical free-riding phenomenon consistently characterising the issue of privately financing the supply of a public good. ${ }^{3}$

An additional implication of the ensuing analysis is close in spirit to one of the backbones of the literature on $R \& D$ incentives, related with the consequences of market structure (or the intensity of competition) and the innovation incentives at the industry level, dating back to the debate between Schumpeter (1942) and Arrow (1962). In this respects, the two models investigated here convey the message that aggregate exploration efforts are non-decreasing in the number of firms operating in the industry. Although

\footnotetext{
${ }^{2}$ On this, see, in particular, the debate between Dasgupta, Gilbert and Stiglitz (1983), Gallini, Lewis and Ware (1983) and Olsen (1988).

${ }^{3}$ See Fershtman and Nitzan (1991), Xie (1997), Karp and Lee (2003) and Cellini and Lambertini (2007), among others.
} 
preliminary, as the settings proposed here are far from general, this conclusion clearly speaks in favour of the Arrovian position.

\section{Model I}

Examine an industry consisting of $n$ single-product firms exploiting a nonrenewable resource over continuous time $t \in[0, \infty)$ to produce a final good which is differentiated as in Singh and Vives (1984), so that each firm $i$ faces the instantaneous demand function

$$
p_{i}(t)=a-q_{i}(t)-s Q_{-i}(t),
$$

where $Q_{-i}(t)=\sum_{j \neq i} q_{j}(t)$ is the collective output of rivals, $a>0$ is the reservation (or choke) price and $s \in[0,1]$ measures the degree of substitutability between any pair of varieties. At any time during the game, the individual cost function is

$$
C_{i}(t)=c q_{i}^{2}(t)+\beta k_{i}^{2}(t),
$$

the first term accounting for extraction and production costs, the second for exploration costs, $k_{i}(t) \geq 0$ being the exploration effort. Function (2) says that all of the firm's activities take place at decreasing returns to scale.

Accordingly, firm $i$ 's profit function is

$$
\pi_{i}(t)=\left[p_{i}-c q_{i}(t)\right] q_{i}(t)-\beta k_{i}^{2}(t) .
$$

In the remainder, I will investigate the two alternative scenarios in which firms either hold private rights on $n$ single pools, one for each firm, or jointly (but noncooperatively) extract the resource from a single common pool.

\subsection{Private pools}

Suppose each firm is allowed to explore its own drilling ground in order to expand it. The volume of resource existing at any $t$ is $x_{i}(t)$, and its dynamics is described by the following state equation:

$$
\dot{x}_{i}(t)=v x_{i}(t) k_{i}(t)-q_{i}(t)
$$

where $v>0$ is a constant common to all firms. It is worth noting that establishes that exploration is effective insofar as the stock has not been altogether exhausted. 
Firm $i$ 's current value Hamiltonian is

$$
\mathcal{H}_{i}(\mathbf{x}, \mathbf{q}, \mathbf{k})=e^{-\rho t}\left[\left(p_{i}-c q_{i}(t)\right) q_{i}(t)-\beta k_{i}^{2}(t)+\lambda_{i}\left(v x_{i}(t) k_{i}(t)-q_{i}(t)\right)\right]
$$

which the firm has to maximise w.r.t. controls $q_{i}(t)$ and $k_{i}(t)$, given the set of initial conditions $x_{i 0}=x_{i}(0)>0$. In $(5), \lambda_{i}(t)=\mu_{i}(t) e^{\rho t}$ is the 'capitalised' costate variable, while $\rho>0$ is the constant discount rate, common to all firms. The solution concept is the open-loop Nash equilibrium. ${ }^{4}$

The necessary conditions are

$$
\begin{gathered}
\frac{\partial \mathcal{H}_{i}(\cdot)}{\partial q_{i}}=a-2(1+c) q_{i}-s Q_{-i}(t)-\lambda_{i}=0 \\
\frac{\partial \mathcal{H}_{i}(\cdot)}{\partial k_{i}}=\lambda_{i} v x_{i}-2 \beta k_{i}=0 \\
\dot{\lambda}_{i}=\left(\rho-v k_{i}\right) \lambda_{i}
\end{gathered}
$$

and the transversality condition is $\lim _{t \rightarrow \infty} e^{-\rho t} \lambda_{i} x_{i}=0$ for each firm. At this point, observe that (8) admits the solution $\lambda_{i}=0$ at all times; this, if substituted back into (7), implies $k_{i}=0$ at all times as well. That is, there exist a solution driving the industry to exploit the natural resources without caring about the ultimate consequence, i.e., exhaustion. This depicts a perspective in which firms, as in most of the environmental problems we are accustomed with, do not internalise the consequences of their activities if regulation policies are absent or assumed away.

This, more often than not, is the only possibility when an appropriate policy is not introduced. However, in the present model there exist an alternative and much more productive route that firms can take spontaneously, and it is the following. From (7), we obtain the expression for the optimal value of the costate variable:

$$
\lambda_{i}=\frac{2 \beta k_{i}}{v x_{i}}
$$

\footnotetext{
${ }^{4}$ The technical reason for this choice is that the model does not take a linear-quadratic form, or any other form for which an obvious candidate for the value function to be used under feedback information is available (see Dockner et al. 2000, ch. 7). There are, however, sound economic arguments that can be invoked to corroborate the adoption of open-loop rules in dynamic games of resource extraction (see Reinganum and Stokey, 1985; and Mohr, 1988).
} 
and the control dynamics:

$$
\dot{k}_{i}=\frac{v\left(\dot{\lambda}_{i} x_{i}+\dot{\lambda}_{i} x_{i}\right)}{2 \beta}
$$

Imposing symmetry across states and controls, and using (9), (6) rewrites as follows:

$$
a-[2(1+c)+s(n-1)] q-\frac{2 \beta k}{v x}=0,
$$

which delivers the optimal Cournot-Nash output ${ }^{5}$

$$
q^{N}=\frac{a v x-2 \beta k}{v[2(1+c)+s(n-1)] x}
$$

at every instant, including the steady state, with no need of deriving the kinematic equation of the individual quantity (i.e., in a quasi-static way).

Then, (4) and (10) become

$$
\begin{gathered}
\dot{x}=\frac{v^{2} k[2(1+c)+s(n-1)] x^{2}-a v x+2 \beta k}{v[2(1+c)+s(n-1)] x} ; \\
\dot{k}=\frac{k[2 \beta k-v x(a-r(2(1+c)+s(n-1)) x)]}{v[2(1+c)+s(n-1)] x^{2}} .
\end{gathered}
$$

Imposing stationarity on the system (13-14), we obtain the coordinates of the steady state points in the space $(x, k)$ :

$$
x_{P P}^{*}=\frac{a v \pm \sqrt{a^{2} v^{2}-8 \beta \rho^{2}[2(1+c)+s(n-1)]}}{2 v[2(1+c)+s(n-1)] \rho} ; k_{P P}^{*}=\frac{\rho}{v} .
$$

Note that $a^{2} v^{2}>8 \beta \rho^{2}[2(1+c)+s(n-1)]$ is necessary and sufficient for $x_{ \pm}^{*} \in \mathbb{R}^{+}$. In the remainder, I will assume this condition is satisfied.

Before delving into any further analytical details of the game, we may pause to stress that (15) illustrates a striking but quite intuitive difference between the firms' incentives when pollution and natural resources are, alternatively at stake, since profit-seeking agents will obviously tend to internalise the effects of their productive activities if these may ultimately jeopardise

\footnotetext{
${ }^{5}$ Henceforth, superscript $N$ will be used to indicate the Cournot-Nash output level, while starred values will refer to the steady state equilibrium.
} 
their ability to extract surplus from consumers (which is more likely to be the case of natural resources than polluting emissions, all else equal). As a consequence, firms do invest positive amounts of resources in exploration even if - as here - they are not spurred to do so by any public policy.

Back to the model, the solutions in (15) can be studied by linearising the system around the steady states, and examine the following $2 \times 2$ Jacobian matrix:

$$
J=\left[\begin{array}{cc}
\frac{\partial \dot{x}}{\partial x} & \frac{\partial f \dot{x}}{\partial k} \\
\frac{\partial \dot{k}}{\partial x} & \frac{\partial \dot{k}}{\partial k}
\end{array}\right]
$$

whereby the stability properties of the state-control dynamics (13-14) depend on the sign and size of the trace $\mathcal{T}(J)$ and determinant $\Delta(J)$ of the above Jacobian matrix:

$$
\begin{gathered}
\mathcal{T}(J)=\frac{2 \beta k-v[a-(2(1+c)+s(n-1))(v k+\rho) x] x}{v[2(1+c)+s(n-1)] x^{2}} \\
\Delta(J)=\frac{k\left[2 \beta(4 v k-\rho)-v^{2}(2 a-\rho(2(1+c)+s(n-1)) x) x\right]}{v[2(1+c)+s(n-1)] x^{2}}
\end{gathered}
$$

In correspondence of the 'smaller' solution, $\left(x_{P P_{-}}^{*}, k^{*}\right)$, we have $\left.\mathcal{T}(J)\right|_{x_{-}^{*}}=$ $\rho>0$ and

$$
\begin{aligned}
& \left.\Delta(J)\right|_{x_{P P-}^{*}} \propto a^{2} v^{2}-8 \beta \rho^{2}[2(1+c)+s(n-1)] \\
& +a v \sqrt{a^{2} v^{2}-8 \beta \rho^{2}[2(1+c)+s(n-1)]}>0 .
\end{aligned}
$$

Moreover, it can be shown that $\left.\Delta(J)\right|_{x_{P P-}^{*}}>\left(\left.\mathcal{T}(J)\right|_{x_{P P-}^{*}}\right)^{2} / 4$. Consequently, $\left(x_{P P_{-}}^{*}, k_{P P}^{*}\right)$ is an unstable focus.

On the contrary, in correspondence of the 'larger' solution, $\left(x_{P P+}^{*}, k_{P P}^{*}\right)$, while we have again $\left.\mathcal{T}(J)\right|_{x_{P P+}^{*}}=\rho>0$, we see that

$$
\begin{aligned}
& \left.\Delta(J)\right|_{x_{P P+}^{*}} \propto a^{2} v^{2}-8 \beta \rho^{2}[2(1+c)+s(n-1)] \\
& -a v \sqrt{a^{2} v^{2}-8 \beta \rho^{2}[2(1+c)+s(n-1)]}<0,
\end{aligned}
$$

which qualifies $\left(x_{P P+}^{*}, k_{P P}^{*}\right)$ as a saddle point. 
Finally, for the sake of completeness, it is worth noting that $\dot{k}=0$ is also satisfied by $k=0$, in which case, however, $\dot{x}<0$ everywhere - which is obvious, as exploitation without exploration leads inevitably to depletion. Additionally, in correspondence of $k=0$ the determinant of the Jacobian matrix is nil, and therefore we may disregard this special case as it is clearly unstable.

The foregoing discussion can be summarised in the following claim:

Proposition 1 The private pool game produces a unique stable steady state equilibrium in $\left(x_{P P+}^{*}, k_{P P}^{*}\right)$, which is a saddle point.

So far, we have dwelt upon the characterization of the equilibrium and its stability properties. However, an interesting qualitative feature of the saddle point is that it has a definite Arrovian flavour. This is self evident, as the optimal steady state investment $k_{P P}^{*}$ is independent of industry structure, and therefore, at the aggregate level, the investment in exploration is monotonically increasing in the number of firms:

$$
K_{P P}^{*}=n k_{P P}^{*}=\frac{n \rho}{v} \Rightarrow \frac{\partial K_{P P}^{*}}{\partial n}=k_{P P}^{*}>0 .
$$

This very fact proves a key result, stated in the following:

Corollary 1 At the steady state, the industry exploration effort is monotonically increasing in the intensity of market competition.

\subsection{Commons}

What if, instead, all firms must exploit a common pool resource, all else equal? The model is unmodified except for a relevant feature, i.e., the presence of a single state $x$, whose dynamic equation is

$$
\dot{x}=v x(t) \sum_{i=1}^{n} k_{i}(t)-\sum_{i=1}^{n} q_{i}(t) .
$$

Firm $i$ 's current-value Hamiltonian is

$$
\begin{gathered}
\mathcal{H}_{i}(x, \mathbf{q}, \mathbf{k})=e^{-\rho t}\left[\left(p_{i}-c q_{i}(t)\right) q_{i}(t)\right. \\
\left.-\beta k_{i}^{2}(t)+\lambda_{i}\left(v x(t)\left(k_{i}(t)+K_{-i}(t)\right)-q_{i}(t)-Q_{-i}(t)\right)\right]
\end{gathered}
$$


where $K_{-i}(t)=\sum_{j \neq i} k_{j}(t)$ and $Q_{-i}(t)=\sum_{j \neq i} q_{j}(t)$, accompanied by the initial condition $x_{0}=x(0)>0$. This produces the set of necessary conditions:

$$
\begin{gathered}
\frac{\partial \mathcal{H}_{i}(\cdot)}{\partial q_{i}}=a-2(1+c) q_{i}-s Q_{-i}(t)-\lambda_{i}=0 \\
\frac{\partial \mathcal{H}_{i}(\cdot)}{\partial k_{i}}=\lambda_{i} v x-2 \beta k_{i}=0 \\
\dot{\lambda}_{i}=\left[\rho-v\left(k_{i}+K_{-i}\right)\right] \lambda_{i}
\end{gathered}
$$

and the transversality condition is $\lim _{t \rightarrow \infty} e^{-\rho t} \lambda_{i} x_{i}=0$ for each firm. Proceeding much the same way as in the previous version of the model, we can verify that

Proposition 2 The common pool game produces a unique stable steady state equilibrium in

$$
x_{C P}^{*}=\frac{a n v+\sqrt{a^{2} n^{2} v^{2}-8 \beta \rho^{2}[2(1+c)+s(n-1)]}}{2 v[2(1+c)+s(n-1)] \rho} ; k_{C P}^{*}=\frac{\rho}{n v},
$$

which is a saddle point.

The proof is omitted for the sake of brevity, as it closely replicates the analysis conducted to prove Proposition 1.

The relevant implication of this result is that, here, the individual equilibrium effort is monotonically decreasing in $n$, while the aggregate effort is altogether independent of industry structure; so, it is neither Arrovian nor Schumpeterian:

Corollary 2 When exploiting a common pool resource, the individual incentive to invest in exploration decreases in the intensity of competition, while the industry effort is independent of industry structure.

This, of course, is the consequence of free riding, which also reflects into the fact that $n k_{C P}^{*}=k_{P P}^{*}$, i.e.,

Corollary 3 The aggregate exploration effort exerted in expanding a common pool is exactly equal to the optimal effort that each firm would exert if it were allowed to exploit a private pool of its own.

In a nutshell, this Corollary grasps the essence of the underprovision of a public good. 


\section{$3 \quad$ Model II}

As an alternative example, I will illustrate a differential oligopoly game of investment in resource exploration that borrows some essential elements from Cellini and Lambertini (2002), where a similar state equation is used for the purpose of studying investment in product differentiation.

\subsection{Private pools}

As in the previous section, a population of $n$ firms sell over time $t \in[0, \infty)$ a homogeneous good whose instantaneous demand function is hyperbolic, $p(t)=a / Q(t) .{ }^{6}$ Production requires a natural resource which, in this setting, is nonrenewable and distributed across the population of firms, each one holding exclusive property rights on an initial endowment $x_{i}(0)>0$. Each firm may independently 'drill the ground' to expand its private pool while exploiting it to supply the final good, the individual state equation being

$$
\dot{x}_{i}=\frac{v x_{i}(t) k_{i}(t)}{1+k_{i}(t)}-q_{i}(t) .
$$

In (27), $k_{i}(t) \geq 0$ is the exploration effort, and $v>0$ is a constant common to all firms. The shape of the exploration function appearing in the above state kinematics says that exploration activities are affected by decreasing returns to scale.

As compared to the previous model, the cost side also changes. Assuming a linear instantaneous cost of exploration efforts, $\Gamma_{i}(t)=\beta k_{i}(t)$, and, for simplicity, a CRS technology for the final good with an average and marginal cost normalised to zero, the instantaneous profits of firm $i$ are

$$
\pi_{i}(t)=\frac{a q_{i}(t)}{q_{i}(t)+Q_{-i}(t)}-\beta k_{i}(t)
$$

whose flow is discounted exponentially at rate $\rho>0$. Therefore, firms play a differential game with $2 n$ controls (outputs $\mathbf{q}$ and efforts $\mathbf{k}$ ) and $n$ states (the vector of private resource pools $\mathbf{x}$ ). The solution concept is the open-loop Nash equilibrium.

\footnotetext{
${ }^{6}$ The assumption of a hyperbolic demand function, of course, is the consequence of the implicit assumption of a Cobb-Douglas utility function for the representative consumer. This possibility is usually left aside for technical reasons, while being empirically relevant. For a discussion, see Lambertini (2010).
} 
Firm $i$ 's Hamiltonian is

$$
\mathcal{H}_{i}(\mathbf{x}, \mathbf{q}, \mathbf{k})=e^{-\rho t}\left[\frac{a q_{i}(t)}{q_{i}(t)+Q_{-i}(t)}-\beta k_{i}(t)+\lambda_{i}\left(\frac{v x_{i}(t) k_{i}(t)}{1+k_{i}(t)}-q_{i}(t)\right)\right] .
$$

Before proceeding, it is worth noting that, as in Model $\mathrm{I}$, also here no costate is assigned to the state equation of any rival firm $j \neq i$ because $\left(\mathbf{q}_{-i}, \mathbf{k}_{-i}\right)$ do not appear in (27).

The necessary conditions are ${ }^{7}$

$$
\begin{aligned}
\frac{\partial \mathcal{H}_{i}(\cdot)}{\partial q_{i}} & =\frac{a Q_{-i}}{\left(q_{i}+Q_{-i}\right)^{2}}-\lambda_{i}=0 \\
\frac{\partial \mathcal{H}_{i}(\cdot)}{\partial k_{i}} & =\frac{\lambda_{i} v x_{i}-\beta\left(1+k_{i}\right)^{2}}{\left(1+k_{i}\right)^{2}} \\
\dot{\lambda}_{i} & =\left(\rho-\frac{v k_{i}}{1+k_{i}}\right) \lambda_{i}
\end{aligned}
$$

and the transversality condition is $\lim _{t \rightarrow \infty} e^{-\rho t} \lambda_{i} x_{i}=0$ for each firm. As in Model I, here again $\lambda_{i}=0$ is a viable solution at any time, but of course I will investigate the alternative route.

From (31), one obtains

$$
\lambda_{i}=\frac{\beta\left(1+k_{i}\right)^{2}}{v x_{i}}>0
$$

and

$$
k_{i}=-1 \pm \sqrt{\frac{\lambda_{i} v x_{i}}{\beta}} .
$$

Since $\lambda_{i}$ is positive, from (34) one has to select the larger root, which can be differentiated w.r.t. time to generate the control equation describing the evolution of the optimal research effort over time:

$$
\dot{k}_{i}=\frac{\sqrt{v}\left(\dot{\lambda}_{i} x_{i}+\lambda_{i} \dot{x}_{i}\right)}{2 \sqrt{\beta \lambda_{i} x_{i}}}
$$

\footnotetext{
${ }^{7}$ Here, as well as in the following case, the stability analysis is omitted for the sake of brevity.
} 
The latter can be simplified using (27), (32) and (33):

$$
\dot{k}_{i}=\frac{\left(1+k_{i}\right)\left(\rho x_{i}-q_{i}\right)}{2 x_{i}} .
$$

Now impose symmetry across states and controls, and note that the use of (33) also makes it redundant to derive a control equation for the output level, that can be determined on the basis of the corresponding FOC, being equal to

$$
q^{N}(x)=\frac{a(n-1) v x}{\beta(1+k)^{2} n^{2}}
$$

at any time, for any given individual stock $x$. The expression of $q^{C N}(x)$ can be substituted back into (27), to verify that

$$
\dot{x}=\frac{\left[\beta k(1+k) n^{2}-a(n-1)\right] v x}{\beta(1+k)^{2} n^{2}}
$$

which is nil in correspondence of $x=0$ (i.e., when the resource is totally depleted) or

$$
k_{P P}^{*}=\frac{1}{2}\left(\frac{\sqrt{4 a(n-1)+\beta n^{2}}}{n \sqrt{\beta}}-1\right)
$$

which is positive for all admissible values of parameters $\{a, n, \beta\} .^{8}$

Carrying in mind the debate between Schumpeter (1942) and Arrow (1962) on the interplay between market power and R\&D incentives, the same exercise as in the previous section can be carried out on the effects of competition or industry structure on the individual and aggregate research efforts, noting that

$$
\frac{\partial k_{P P}^{*}}{\partial n} \propto a(2-n)
$$

which is positive for $n=1$, nil in duopoly and negative for all $n \geq 3$, while

$$
\frac{\partial\left(n k_{P P}^{*}\right)}{\partial n} \propto 2 a+n \beta-\sqrt{\beta\left[4 a(n-1)+\beta n^{2}\right]}>0
$$

for all $\{a, n, \beta\}$. This immediately reveals the following:

Proposition 3 A concave relationship exists between individual research efforts and industry structure. Instead, the aggregate research effort of the industry increases monotonically in the intensity of market competition (the number of firms), a result which has a definite Arrovian flavour.

\footnotetext{
${ }^{8}$ The smaller root can be disregarded as it is negative.
} 


\subsection{Commons}

Let's have a look at the alternative case in which firms jointly (but still noncooperatively) exploit a single pool. In this scenario, the single state dynamics is

$$
\dot{x}=\frac{v x(t) \sum_{i=1}^{n} k_{i}(t)}{1+\sum_{i=1}^{n} k_{i}(t)}-\sum_{i=1}^{n} q_{i}(t) .
$$

The remainder of the model being unmodified, firm $i$ 's Hamiltonian is

$$
\begin{aligned}
& \mathcal{H}_{i}(x, \mathbf{q}, \mathbf{k})=e^{-\rho t}\left[\frac{a q_{i}(t)}{q_{i}(t)+Q_{-i}(t)}-\beta k_{i}(t)+\right. \\
& \left.\lambda_{i}\left(\frac{v x(t)\left(k_{i}(t)+K_{-i}(t)\right)}{1+k_{i}(t)+K_{-i}(t)}-q_{i}(t)-Q_{-i}(t)\right)\right]
\end{aligned}
$$

where $K_{-i}(t)=\sum_{j \neq i} k_{j}(t)$ and $Q_{-i}(t)=\sum_{j \neq i} q_{j}(t)$. The necessary conditions are

$$
\begin{gathered}
\frac{\partial \mathcal{H}_{i}(\cdot)}{\partial q_{i}}=\frac{a Q_{-i}}{\left(q_{i}+Q_{-i}\right)^{2}}-\lambda_{i}=0 \\
\frac{\partial \mathcal{H}_{i}(\cdot)}{\partial k_{i}}=\frac{\lambda_{i} v x_{i}-\beta\left(1+k_{i}+K_{-i}\right)^{2}}{\left(1+k_{i}\right)^{2}} \\
\dot{\lambda}_{i}=\left(\rho-\frac{v\left(k_{i}+K_{-i}\right)}{1+k_{i}++K_{-i}}\right) \lambda_{i}
\end{gathered}
$$

and the transversality condition is $\lim _{t \rightarrow \infty} e^{-\rho t} \lambda_{i} x=0$ for each firm.

Proceeding as in the previous case, one obtains

$$
\dot{x}=\frac{\left[\beta k(1+n k) n^{2}-a(n-1)\right] v x}{\beta(1+k)^{2} n^{2}},
$$

which is nil at either $x=0$ or

$$
k_{C P}^{*}=\frac{1}{2 n}\left(\frac{\sqrt{4 a(n-1)+\beta n}}{\sqrt{n \beta}}-1\right)
$$

with

$$
\frac{\partial\left(n k_{C P}^{*}\right)}{\partial n}=\frac{a}{n \sqrt{n \beta[4 a(n-1)+\beta n]}}>0
$$

This proves 
Proposition 4 In Model II, the aggregate investment in exploration monotonically increases in the size of firms' population also when a common pool is exploited.

Hence, it seems that the aggregate behaviour may reflect the Arrovian hypothesis if appropriate conditions hold.

Comparing individual exploration efforts reveals that

$$
k_{C P}^{*}-k_{P P}^{*} \propto-2(n-1)[2 a(n-1)+n \beta-\sqrt{n \beta[4 a(n-1)+\beta n]}]<0
$$

so that exploiting a common pool leads firms (and the industry as a whole) to underinvest in research activity as compared to the case in which each firm enjoys private access to a separate resource pool.

\section{Concluding remarks}

I have investigated two simple differential games based on alternative assumptions on demand and technology, in which Cournot firms, the lack of a resource policy notwithstanding, spontaneously internalise the consequences of profit-seeking behaviour on the residual stock of natural resources, and consequently activate costly exploration projects.

In both settings, the foregoing analysis has shown that private access to a single pool creates higher incentives to invest in exploration than the joint exploitation of a common pool does. Additionally, depending on the specific features on technology and demand, the aggregate exploration effort of the industry is either constant or increasing in the number of firms. The latter case has a definite Arrovian nature.

The elements and conclusions of the present work open a few perspectives to be left for future research, among which (i) the analysis of the consequences of Bertrand behaviour, and its comparison with Cournot, and (ii) the construction of a more comprehensive one in which the natural resource explicitly appears as a factor of production and, possibly as well as desirably, its use also implies a negative environmental externality (as in Lambertini and Leitmann, 2013). 


\section{References}

Arrow, K. (1962), "Economic Welfare and the Allocation of Resources for Invention", in R. Nelson (ed.), The Rate and Direction of Industrial Activity, Princeton, NJ, Princeton University Press.

Arrow, K.J. and S. Chang (1982), "Optimal Pricing, Use, and Exploration of Uncertain Resource Stocks", Journal of Environmental Economics and Management, 9, 1-10.

Boyce, J. and L. Vojtassak (2008), "An 'Oil'igopoly Theory of Exploration", Resource and Energy Economics, 30, 428-54.

Cellini, R., and L. Lambertini (2002), "A Differential Game Approach to Investment in Product Diæerentiation", Journal of Economic Dynamics and Control, 27, 51-62.

Cellini, R. and L. Lambertini (2007), "Time Consistent Fiscal Policies in a Ramsey Economy", Mathematical Social Sciences, 53, 296-313.

Dasgupta, P., R. Gilbert and J. Stiglitz (1983), "Strategic Considerations in Invention and Innovation: The Case of Natural Resources", Econometrica, 51, 1439-48.

Davison, R. (1978), "Optimal Depletion of an Exhaustible Resource with Research and Development Towards an Alternative Technology", Review of Economic Studies, 45, 335-67.

Deshmuk, S.D. and S.R. Pliska (1980), "Optimal Consumption and Exploration of Nonrenewable Resources under Uncertainty", Econometrica, 48, 177-200.

Dockner, E.J, S. Jørgensen, N. Van Long and G. Sorger (2000), Differential Games in Economics and Management Science, Cambridge, Cambridge University Press.

Fershtman, C. and S. Nizan (1991), "Dynamic Voluntary Provision of Public Goods", European Economic Review, 35, 1057-67. 
Gallini, N., T. Lewis and R. Ware (1983), "Strategic Timing and Pricing of a Substitute in a Cartelized Resource Market", Canadian Journal of Economics, 16, 429-46.

Harris, C. and J. Vickers (1995), "Innovation and Natural Resources: A Dynamic Game with Uncertainty", RAND Journal of Economics, 26, 418-30.

Hoel, M. (1978), "Resource Extraction, Substitute Production, and Monopoly", Journal of Economic Theory, 19, 28-77.

Hoel, M. (1983), "Monopoly Resource Extractions under the Presence of Predetermined Substitute Production", Journal of Economic Theory, 30, 201-12.

Karp, L. and I.H. Lee (2003), "Time-Consistent Policies", Journal of Economic Theory, 112, 353-64.

Lambertini, L. (2010), "Oligopoly with Hyperbolic Demand: A Differential Game Approach", Journal of Optimization Theory and Applications, 145, 108-19.

Lambertini, L. (2013), Oligopoly, the Environment and Natural Resources. Incentives, Regulation and Sustainability, London, Routledge, forthcoming.

Lambertini, L. and G. Leitmann (2013), "Market Power, Resource Extraction and Pollution: Some Paradoxes and a Unified View", in J. Crespo Cuaresma, T. Palokangas and A. Tarasjev (eds), Green Growth and Sustainable Development, Heidelberg, Springer, forthcoming.

Loury, G. (1986), "A Theory of 'Oil'Igopoly: Cournot Equilibrium in Exhaustible Resource Markets with Fixed Supplies", International Economic Review, 27, 285-301.

Mohr, E. (1988), "Appropriation of Common Access Natural Resources Through Exploration: The Relevance of the Open-Loop Concept", International Economic Review, 29, 307-20.

Olsen, T.E. (1988), "Strategic Considerations in Invention and Innovation: The Case of Natural Resources Revisited", Econometrica, 56, 841-49. 
Peterson, F.M. (1978), "A Model of Mining and Exploration for Exhaustible Resources", Journal of Environmental Studies and Management, 5, $236-51$.

Polasky, S. (1992a), "Do Oil Firms Act as 'Oil'Igopolists?", Journal of Environmental Economics and Management, 23, 216-47.

Polasky, S. (1992b), "Exploration and Extraction in a Duopoly-Exhaustible Resource Market", Canadian Journal of Economics, 29, 473-92.

Quyen, N.V. (1988), "The Optimal Depletion and Exploration of a Nonrenewable Resource", Econometrica, 56, 1467-71.

Quyen, N.V. (1991), "Exhaustible Resources: A Theory of Exploration", Review of Economic Studies, 58, 777-89.

Reinganum, J. and N. Stokey (1985), "Oligopoly Extraction of a Common Property Resource: The Importance of the Period of Committment in Dynamic Games", International Economic Review, 26, 161-73.

Salant, S. (1976), "Exhaustible Resources and Industrial Structure: A NashCournot Approach to the World Oil Market", Journal of Political Economy, 84, 1079-94.

Schumpeter, J.A. (1942), Capitalism, Socialism and Democracy, New York, Harper.

Singh, N. and X. Vives (1984), "Price and Quantity Competition in a Differentiated Duopoly", RAND Journal of Economics, 15, 546-54.

Xie, D. (1997), "On Time Consistency: A Technical Issue in Stackelberg Differential Games", Journal of Economic Theory, 76, 412-30. 


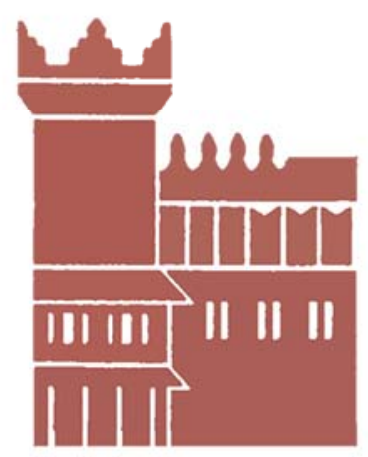

Alma Mater Studiorum - Università di Bologna DEPARTMENT OF ECONOMICS

Strada Maggiore 45

40125 Bologna - Italy

Tel. +39051 2092604

Fax +390512092664

http://www.dse.unibo.it 